mental hospital unit, and 62 normal controls. Serum vitamin $B_{12}$ estimations were also done on 368 of the patients. Though patients and controls did not differ on mean serum folate, there were significantly more patients with values below $2 \mathrm{~m} \mu \mathrm{g} . / \mathrm{ml}$. ("low folate") than controls. Patients with epilepsy, organic psychoses, and endogenous depression had significantly lower mean serum folate, and chronic alcoholics significantly higher mean serum folate, than the controls; the former conditions also predominated among patients with low folate, a diagnostic pattern significantly at variance from that of patients with normal folate values and those with serum $B_{12}<150 \mu \mu \mathrm{g} . / \mathrm{ml}$. Low folate patients had more haematological abnormalities, including low serum $B_{12}$, than other patients; $75.2 \%$ had received drugs during the three weeks before admission, $22.9 \%$ showed evidence of malnutrition, $17 \%$ were physically ill, and $44.2 \%$ had been continuously ill for more than three years.

I wish to thank Drs. F. Yates, P. Harvey, and F. Hayes, Messrs. Orrell, Curd, Singleton, and Kilgarriff, and Sisters Hetherington and Morton for advice and co-operation; and Mrs. J. Taylor and Mrs. E. Jackson for clerical assistance.

\section{REFERENCES}

Batata, M., Spray, G. H., Bolton, F. G., Higgins, G., and Wollner, L. (1967). Brit. med. Ұ., 2, 667.

Forshaw, J. (1965). Ibid., 2, 1061.

- Moorhouse, E. H., and Harwood, L. (1964). Lancet, 1, 1004. Gough, K. R., Read, A. E., McCarthy, C. F., and Waters, A. H. (1963). Quart. 7. Med., 32, 243.

Grant, H. C., Hoffbrand, A. V., and Well, D. G. (1965). Lancet, 2, 763 Henderson, J. G., Strachan, R. W., Beck, J. S., Dawson, A. A., and Daniel, M. (1966). Ibid., 2, 809.

Herbert, V., Gottlieb, C. W., and Altschule, M. D. (1965). Ibid., 2, 1052. Klipstein, F. A. (1964). Blood, 23, 68.

Magnus, E. M. (1966). Lancet, 2, 341.

Malpas, J. S., Spray, G. H., and Witts, L. J. (1966). Brit. med. 7., $1,955$.

Read, A. E., Gough, K. R., Pardoe, J. L., and Nicholas, A. (1965). Ibid., $2,843$.

Reynolds, E. H. (1966). Communication to the 4th World Congress of Psychiatry, Madrid, 1966

(1967). Brit. F. Psychiat. 113, 681.

Shulman, R (1967). Ibid., 113, 241.

Waters, A. H., and Mollin, D. L. (1961). F. clin. Path., 14, 335.

\title{
Ascorbic Acid Nutrition in Gastroduodenal Disorders
}

\author{
MAX M. COHEN,* M.B., CH.B.; ANNE M. DUNCAN, $\dagger$ B.SC.
}

Frank clinical scurvy is a rare disease, but subclinical deficiency of ascorbic acid, as defined by low dietary intake of ascorbic acid and low blood levels, is common. Thus the significance of "subvitaminosis C" has been the subject of controversy since it was first described by Hess (1917). However, it is probably now accepted that, while under normal circumstances a low intake of ascorbic acid is harmless (Dahlberg, Engel, and Rydin, 1944), at times of stress, when there is increased utilization of ascorbic acid by the tissues generally (Faulkner and Taylor, 1937) and especially by wounded tissues (Crandon, Landau, Mikal, Balmanno, Jefferson, and Mahoney, 1958), dietary deficiency may render the patient vulnerable to infection (Heise and Martin, 1936) and the low blood ascorbic acid level may make the surgical patient more liable to wound dehiscence (Crandon, Lennihan, Mikal, and Reif, 1961).

Attention has recently been drawn to the low levels of leucocyte ascorbic acid seen in large numbers of surgical patients (Crandon et al., 1961), in elderly patients (Bowers and Kubik, 1965), and particularly in patients with peptic disorders (Cohen, 1967).

The fundamental importance of vitamin $C$ in the healing process has been demonstrated in guinea-pigs (Bourne, 1944 ; Penney and Balfour, 1949 ; Gould, 1958 ; Ellis, Harrison, and Hugh, 1965) and in humans (Hunt, 1941 ; Boyd and Campbell, 1950), the two animal species known not to synthesize ascorbic acid. It is therefore important to understand the significance of the low blood levels of ascorbic acid consistently found in patients with peptic ulcer (Harris, Abbasy, Yudkin, and Kelly, 1936 ; Platt, 1936 ; Archer and Graham, 1936; Lazarus, 1937 ; Portnoy and Wilkinson, 1938), as in these patients surgery is often the treatment of choice.

In this investigation we have attempted to assess the extent of ascorbic acid deficiency in surgical patients, and in particular in those with duodenal ulcer, using the leucocyte ascorbic acid level, as this is now accepted as the best available index of ascorbic acid nutrition (Bartley, Krebs, and O'Brien, 1953), and to relate these findings to dietary intake of ascorbic acid.

\footnotetext{
- Department of Surgery, Glasgow Royal Infirmary. Present appointment: Surgical Registrar, Western Infirmary, Glasgow W.1. † Department of Biochemistry, Glasgow Royal Infirmary, Glasgow C4.
}

\section{Method}

Leucocyte ascorbic acid levels were estimated by the method of Denson and Bowers (1961). Particular care was taken to avoid delays of more than several minutes between venepuncture and beginning the initial fractionation of the blood, as white blood cells take up ascorbic acid from the plasma on standing. Simultaneous estimations were made of the white blood cell count and platelet count to allow any necessary conversion factor to be applied (Gibson, Moore, and Goldberg, 1966) ; but in fact all of these counts fell within the accepted normal range and thus no conversion factor was necessary. The levels of ascorbic acid quoted subsequently represent the total ascorbic acid present in the white cells plus the platelets, though conventionally expressed as microgrammes per hundred million white blood cells ( $\mu$ g. $/ 10^{8}$ W.B.C.).

The leucocyte ascorbic acid levels were estimated in 14 normal healthy young adults, all of whom were known to have an intake of ascorbic acid of at least $30 \mathrm{mg}$./day, the level of intake recommended by the Medical Research Council (Bartley et al., 1953) and adopted by the British Medical Association.

A random sample of 50 patients admitted to a general surgical unit in a large city teaching hospital was investigated. All were admitted during November or December, a time of year when the autumn peak of ascorbic acid nutrition (National Food Survey Committee, 1966) would still be reflected in the leucocyte ascorbic acid level and above average levels could reasonably be expected. Dietary histories were obtained from all patients and normal subjects by one of us (M.M.C.) using a questionary based on the tables of McCance and Widdowson (1960).

Of the 50 patients investigated 14 were found to be suffering from some gastroduodenal disorder, and in all 14 the diagnosis was confirmed at laparotomy. Fourteen surgical patients with no known alimentary disease, matched for age and sex, were used as controls.

Nine of the 14 patients with gastroduodenal disorders had duodenal ulcer alone; all were treated surgically by total vagotomy and pyloroplasty. Eight of them were reviewed five months after surgery (one patient being lost to follow-up). 


\section{Results}

(1) Normals.-In 14 normal young adults (eight male, six female) with a mean age of 22 years (S.D. \pm 1.7 ) and on an adequate diet, the mean leucocyte ascorbic acid level was 21.7 $\mu$ g. $/ 10^{8}$ W.B.C. (S.D. \pm 4.6 ). The range of values was 15.0-29.0 $\mu$ g. $/ 10^{8}$ W.B.C. The mean dietary intake of ascorbic acid was $48 \mathrm{mg} . /$ day (S.D. \pm 19.5 ), the range of values being 30$101 \mathrm{mg}$./day. In these subjects there was no correlation demonstrable between the level of intake of ascorbic acid and the leucocyte ascorbic acid level (Fig. 1).

(2) Control Patients. - In 14 control patients (seven male, seven female) with a mean age of 50 years (S.D. \pm 17.0$)$ and with no known alimentary disease the mean leucocyte ascorbic acid level was $22.9 \mu$ g. $/ 10^{8}$ W.B.C. (S.D. \pm 5.9 ). The mean dietary intake of ascorbic acid in this group was $39 \mathrm{mg}$./day (S.D. \pm 17.3 ). A strong correlation was observed between the ascorbic acid intake and the leucocyte ascorbic acid level (Fig. 2).

(3) Gastroduodenal Disorders.-The mean leucocyte ascorbic acid level in 14 patients (seven male, seven female) with gastroduodenal disorders (mean age 50 years, S.D. \pm 17.0 ) was 11.0 $\mu$ g. $/ 10^{8}$ W.B.C. (S.D. \pm 4.4 ). The mean dietary intake of ascorbic acid was $27 \mathrm{mg}$./day (S.D. \pm 12.5 ). In this group there was fair correlation between the leucocyte ascorbic acid level and the dietary intake of ascorbic acid (Fig. 3).

(4) Duodenal Ulcer Before Surgery.-The mean leucocyte ascorbic acid level in the eight patients (five male, three female) with duodenal ulcer who were subsequently reviewed was 8.7 $\mu$ g. $10^{8}$ W.B.C. (S.D. \pm 1.3 ). The mean dietary intake of ascorbic acid was $27 \mathrm{mg}$./day (S.D. \pm 10.7 ), no correlation being demonstrable between this and the leucocyte ascorbic acid level (Fig. 4).

(5) Duodenal Ulcer After Surgery.-Five months after surgery, when the eight patients (five male, three female) with duodenal ulcer were reviewed, the mean leucocyte ascorbic acid level was found to be $12.8 \mu \mathrm{g} . / 10^{8}$ W.B.C. (S.D. \pm 4.3 ) and the mean dietary intake of ascorbic acid was $53 \mathrm{mg}$./day (S.D. \pm 27.9). The relation between ascorbic acid intake and leucocyte ascorbic acid is shown in Fig. 4.

The results demonstrate no significant difference between the leucocyte ascorbic acid levels or ascorbic acid intakes of normal subjects and control patients. The dietary intake of ascorbic acid was significantly lower in patients with gastroduodenal disorders than in control patients $(P>0.05)$. No difference was demonstrated between the ascorbic acid intake of patients with duodenal ulcer and those with gastroduodenal disorders in general. The leucocyte ascorbic acid levels in patients with gastroduodenal disorders, and particularly duodenal ulcer, were significantly lower than in controls $(P>0.01)$.

While patients with duodenal ulcer had lower leucocyte ascorbic acid levels than patients with gastroduodenal disorders in general, this was not significant. After surgery for duodenal

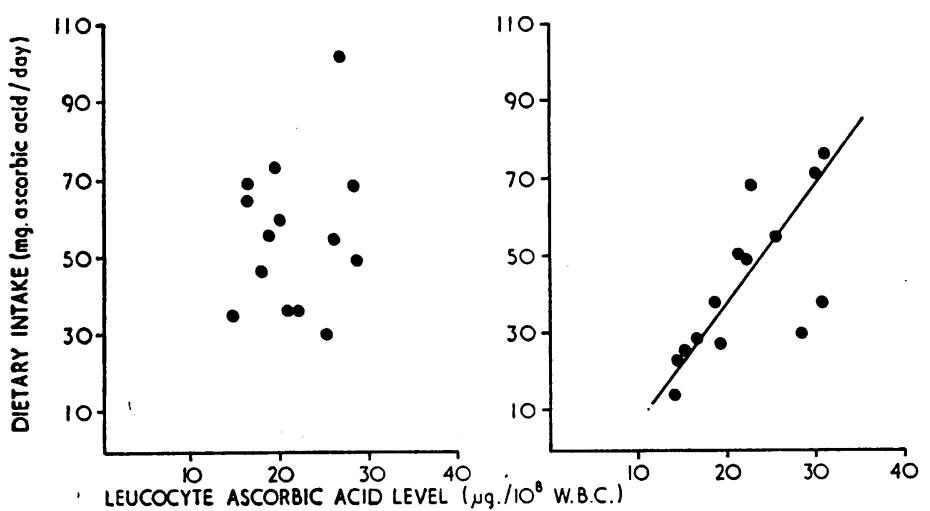

PIG. 1

Fig. 2 ulcer, however, there was a significant rise in the leucocyte ascorbic acid level $(P>0.05)$ and in the dietary intake of ascorbic acid $(\mathrm{P}>0.01)$.

In no patient was there any obvious clinical evidence of scurvy. None of the patients had clinical evidence of steatorrhoea or malabsorption, and in no patient was there any gross upset of haemoglobin level or of the plasma proteins. The patients who were reviewed after surgery for duodenal ulcer were well, offered no dyspeptic symptoms on specific questioning, and in particular none had post-vagotomy diarrhoea.

\section{Discussion}

The leucocyte ascorbic acid level has been shown to be significantly lower in patients with gastroduodenal disorders, and in particular, in duodenal ulcer than in a control group. These patients have also been shown to subsist on a dietary intake of ascorbic acid below the $30 \mathrm{mg}$./day recommended by the British Medical Association (1950) at a time of year when dietary ascorbic acid could normally be expected to be above average. None of the patients subsisted on a "scorbutogenic" diet of less than $10 \mathrm{mg} . /$ day (Bartley et al., 1953).

In patients with gastroduodenal disorders and in controls a correlation has been shown to exist between the dietary intake of ascorbic acid and the leucocytic ascorbic acid level. There was, however, no such correlation demonstrable in normal young adults on high intakes of ascorbic acid nor in patients with duodenal ulcer after surgery.

Low leucocyte ascorbic acid levels have been found in elderly patients (Bowers and Kubik, 1965), and this has been attributed to a reduced dietary intake of ascorbic acid (Andrews and Brook, 1966). Williamson, Goldberg, and Moore (1967) have found low leucocyte ascorbic acid levels in patients with malabsorption and after various gastric operations, in association with a normal intake of ascorbic acid, and they postulate the possibility of this being due to increased utilization of ascorbic acid in these circumstances.

Our findings suggest that the low leucocyte ascorbic acid level found in the patients with gastroduodenal disorder is due to dietary deficiency of ascorbic acid rather than to any increased utilization or malabsorption of ascorbic acid. This correlates well with everyday experience of the dietary habits or patients with dyspepsia.

Experiments in guinea-pigs have shown that ascorbic acid is essential for the formation of mature collagen in wounds (Robertson and Schwartz, 1953 ; Gould, 1958), and, in addition, that there is a definite correlation between the dietary intake of ascorbic acid and the rate of collagen formation (Robertson, 1961). It has also been shown that a dose of less than $5 \mathrm{mg}$. of ascorbic acid per day $(5 \mathrm{mg}$. daily is roughly five times the amount necessary to protect the guinea-pig from
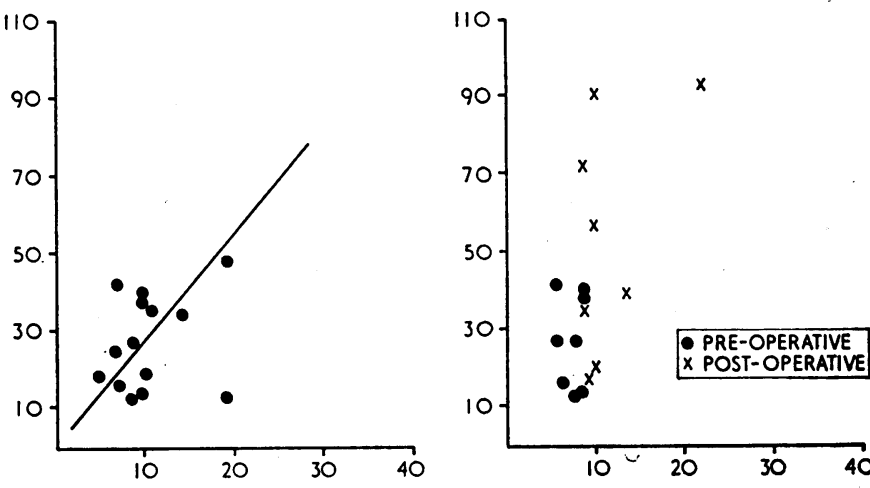

FIG. 3

Fig. 1-Relation of ascorbic acid intake to leucocyte ascorbic acid in 14 young adults. Fig. 2.- Relation of ascorbic acid intake to leucocyte ascorbic acid in 14 control patients. FIG, 3-Relation of ascorbic acid intake to leucocyte ascorbic acid in 14 patients with gastroduodenal disorders. FIG. 4.- Relation of ascorbic acid intake to leucocyte ascorbic acid in eight patients with duodenal uicer. 
scurvy) is not adequate to permit a maximal collagen concentration in guinea-pig experimental carrageenin granulomas (Robertson, 1966).

Because of the technical difficulty of studying human wound healing it is not yet known whether there is a critical level of ascorbic acid nutrition below which wound healing is impaired. But the evidence from guinea-pig experiments, together with the evidence of a high incidence of poor ascorbic acid nutrition in patients suffering the complication of complete wound dehiscence (Crandon et al., 1958), must make us view with concern the low leucocyte ascorbic acid levels we have shown in patients with gastroduodenal disorders.

Until it is shown conclusively that patients with low leucocyte ascorbic acid levels are at no greater risk of impaired wound healing it would appear mandatory that all patients who could be expected to have such low levels be given routine ascorbic acid supplements before surgery and during the phase of early wound healing. This can be done easily and very cheaply by means of oral ascorbic acid tablets, and in emergencies saturation can be achieved by the intravenous route. There are no known hazards of ascorbic acid therapy, and overdosage is therefore of no practical importance.

We have shown that after successful surgery for duodenal ulcer there was the expected return to a normal diet with an adequate intake of ascorbic acid. It is very interesting, however, that though the leucocyte ascorbic acid levels significantly improved after surgery they did not return to normal levels even after five months had elapsed. The turnover half-life of labelled ascorbic acid is approximately 20 days (Baker, Saari, and Tolbert, 1966), so no improvement in ascorbic acid nutrition could be expected with the further passage of time. A possible explanation of this finding is that after vagotomy and pyloroplasty there is a relative malabsorption of ascorbic acid. The absorption of ascorbic acid is impaired by achlorhydria (Alt, Chinn, and Farmer, 1939), so it may be that the therapeutic hypochlorhydria achieved by complete vagotomy is responsible for the failure of a normal diet to correct completely the abnormal leucocyte ascorbic acid levels found in patients with duodenal ulcer.

\section{Summary}

Fourteen patients with gastroduodenal disorders had signiticantly lower levels of leucocyte ascorbic acid than 14 control patients and 14 healthy young adults. The mean leucocyte ascorbic acid level in the test patients was $11.0 \mu \mathrm{g} . / 10^{8}$ W.B.C. and in the control patients was $22.9 \mu \mathrm{g} . / 10^{8}$ W.B.C. $(P>0.01)$.

Eight patients with proved duodenal ulcer had a reduced dietary intake of ascorbic acid and a low level of leucocyte ascorbic acid (mean $8.7 \mu$ g. $/ 10^{8}$ W.B.C.). After vagotomy and pyloroplasty the dietary intake returned to normal and the leucocyte ascorbic acid level increased significantly $(P>0.05)$ though normal levels were not achieved.

The significance of these findings was discussed, and it was recommended that patients with peptic ulcer should have routine supplements of ascorbic acid before surgery is performed and during the period of postoperative convalescence.

We are indebted to Mr. John Hutchison for his encouragement and permission to study patients in his wards, and to Professor H. G. Morgan and Sir David Cuthbertson for helpful advice and criticism. We are grateful to Dr. G. MacDonald for haematological estimations and to Miss Catherine M. Smith for assistance with the dietary investigations.

\section{REFERENCES}

Alt, H. L, Chinn, H., and Farmer, C. J. (1939). Amer. F. med. Sci., 197, 229.

Andrews, J., and Brook, M. (1966). Lancet, 1, 1350 .

Archer, H. E., and Graham, G. (1936). Ibid., 2, 364

Baker, E. M., Saari, J. C., and Tolbert, B. M. (1966). Amer. 3. clin. Nutr., 19, 371.

Bartley, W., Krebs, H. A., and O'Brien, J. R. P. (1953). Spec. Rep. Ser. med. Res. Coun. (Lond.), No. 280.

Bourne, G. H. (1944). Lancet, 1, 688.

Bowers, E. F, and Kubik, M. M. (1965). Brit. F. clin. pract., 19, 141.

Boyd, T. A. S., and Campbell, F. W. (1950). Brit. med. F., 2, 1145.

British Medical Association (1950). Report of the Committee on Nutrtion. London.

Cohen, M. M. (1967). Brit. med. 7., 2, 243.

Crandon, J. H., Landau, B., Mikal, S., Balmanno, J., Jefferson, M., and Mahoney, N. (1958). Ŝ New Engl. ł. Med., 258, 105.

Lennihan, R., Mikal, S., and Reif, A. E. (1961). Ann. N.Y. Acad. Sci., 92, 246.

Dahlberg, G., Engel, A., and Rydin, H. (1944). Acta med. scand., 119, 540

Denson, K. W., and Bowers, E. F. (1961). Clin. Sci., 21, 157.

Ellis, E., Harrison, W., and Hugh, T. B (1965). Brit. F. Surg., 52, 471.

Faulkner. J. M., and Tavlor, F. H. L. (1937). Ann. intern. Med.s 10. 1867.

Gibson, S. I. M., Moore, F. M. L., and Goldberg, A. (1966). Brit. med. 7., 1,1152 .

Gould, B. S. (1958). 7. biol. Chem., 232, 637.

Harris, L. J., Abbasy, M. A., Yudkin, J., and Kelly, S. (1936). Lancet, 1,1488 .

Heise, F. H., and Martin, G. J. (1936). Proc. Soc. exp. Biol. (N.Y.), 34, 642 .

Hess, A. F. (1917). F. Amer. med. Ass., 68, 235.

Hunt, A. H. (1941). Brit. f. Surg., 28, 436.

Lazarus, S. (1937). Brit. med. F., 2, 1011.

McCance, R. A., and Widdowson, E. M. (1960). Spec. Rep. Ser. med. Res. Coun. (Lond.), No. 297.

National Food Survey Committee (1966). Domestic Food Consumption and Expenditure. London.

Penney, J. R., and Balfour, B. M. (1949). F. Path. Bact., 61, 171.

Platt, R. (1936). L'ancet, 2, 366.

Portnoy, B., and Wilkinson, J. F. (1938). Brit. med. 7., 1, 554.

Robertson, W. van B. (1961). Ann. N.Y. Acad. Sci., 92, 159.

(1966). In Wound Healing, edited by S. M. Levenson, J. M. Stein, and N. Grossblatt, p. 304 . W ashington.

- and Schwartz, B. (1953). \%. biol. Chem., 201, 689.

Williamson, J. M., Goldberg, A., and Moore, F. M. L. (1967). Brit. med. f., $2,23$. 